\title{
Comparison of antioxidant capacity of cow and ewe milk kefirs
}

\author{
Lutfiye Yilmaz-Ersan, ${ }^{* 1}$ Tulay Ozcan, ${ }^{*}$ Arzu Akpinar-Bayizit, ${ }^{*}$ and Saliha Sahin† \\ *Department of Food Engineering, Faculty of Agriculture, and \\ †Department of Chemistry, Faculty of Science and Arts, Uludag University, Bursa, Turkey 16059
}

\begin{abstract}
This research aimed to evaluate the effects of using either grain or commercial starter culture on the antioxidative capacity of cow and ewe milk kefirs. The antioxidant capacity of kefir samples during fermentation and $21 \mathrm{~d}$ of storage was assessed by using 3 assays: 2,2'-azino-bis(3-ethylbenzthiazoline-6-sulfonic acid) (ABTS) radical cation decolorization; 2,2-diphenyl1-picrylhydrazyl $\left(\mathrm{DPPH}^{\bullet}\right)$ radical scavenging activity assay; and $\mathrm{Fe}^{+3}$-reducing power (ferric reducing antioxidant power assay, FRAP). Vitamin $\mathrm{E}$ and $\beta$-carotene contents were also quantified. All kefir samples exhibited varying values for DPPH, ABTS, and FRAP assays depending on the starter culture and milk type. Vitamin $\mathrm{E}$ and $\beta$-carotene contents were similar in all kefir samples during storage. The results of this study suggest that milk type (cow or ewe) and culture type (kefir grains or commercial starter) were the significant parameters for the antioxidative activity of kefir.
\end{abstract}

Key words: antioxidant capacity, cow, ewe, milk, kefir

\section{INTRODUCTION}

Some chronic diseases including cancer, cardiovascular disease, and degenerative disease of aging have been related to the oxidative stress caused by excessive production of reactive oxygen species and oxygen-free radicals (Pizzino et al., 2017). Oxidative stress can also increase oxidation of membrane phospholipids, proteins, and DNA, as well as modification of low-density lipoproteins (López-Pedrera et al., 2016). Aerobic organisms are protected from oxidative stress by various enzymatic and nonenzymatic antioxidant defense systems. When the endogenous defense system cannot prevent the damage of reactive radicals, artificial antioxidants, such as butylated hydroxytoluene, butylated hydroxyanisole, and tert-butylhydroquinone, and natural antioxidants are used to impede the detrimental

Received September 22, 2017.

Accepted December 29, 2017.

${ }^{1}$ Corresponding author: lutfiyey@uludag.edu.tr effects of oxidative stress. Because artificial antioxidants have been reported to be toxic, carcinogenic, and unsafe, most consumers prefer natural antioxidants as they believe these are not chemicals and are not subjected to any legislative restrictions of use (Boskou and Elmadfa, 2010; Bartosz, 2013; Landete, 2013).

Milk is a unique food that contains valuable macroand micronutrients for the growth and development of breastfed infants; it is also a basic source of energy and nutritional components for mammals. It has naturally occurring nonenzymatic antioxidants such as vitamins A, C, and E, carotenoids, uric acid, CLA, and enzymatic antioxidants such as catalase, superoxide dismutase, and glutathione peroxidase. Some proteins in milk (e.g., casein, lactoferrin, $\alpha-\mathrm{LA}, \beta-\mathrm{LG}$ ) and milk amino acids such as tyrosine, cysteine, tryptophan, and lysine are known to have antioxidant potential. Therefore, the antioxidant defense system of different animal milk and milk products can be considered to have health-beneficial effects against free radical damage (Lindmark-Månsson and Akesson, 2000; Kullisaar et al., 2003; Kitts, 2005; Zulueta et al., 2009).

Kefir has been manufactured and consumed since ancient times for its nutritional, taste, and flavor properties, as well as its potential health benefits. Consumption of kefir is increasing among consumers because of its profound antimicrobial, antibacterial, antitumor, antihypertensive, antioxidative, anticytotoxic, and hypocholesterolemic effects (de Oliveira Leite et al., 2013; Arslan, 2015; Chen et al., 2015; Prado et al., 2015). Kefir is obtained by the fermentation of milk with mixed microflora, including various species of lactic acid bacteria, acetic acid bacteria, and yeasts. The acid-alcoholic fermentation of milk with these microorganisms results in a refreshing and slightly acidic taste. Kefir is produced by either traditional or industrial methods. Traditional kefir production involves addition of kefir grains, whereas industrial kefir has been produced by commercial starter cultures of pure or mixed-strain cultures in powder form. Different animal milks such as cow, ewe, and goat, and plant-based milks obtained from soy, coconut, and rice can be used for production. The type of milk, type and quantity of starter culture, time and temperature-related conditions of fermenta- 
tion, and storage conditions all affect the microbiological, chemical, and sensorial characteristics of kefir (Gao and Li, 2016; Barukčić et al., 2017; Rosa et al., 2017).

In previous studies, milk and milk products (i.e., yogurt, cheese, whey) were shown to have antioxidant properties depending on the presence and activity of natural bioactive components (Taylor and Richardson, 1980; Korpela et al., 1995; Chen et al., 2003; Pulido et al., 2003; Smet et al., 2008; Gupta et al., 2009; Kesenkas et al., 2011; Perna et al., 2013; Shori and Baba, 2013; Chen et al., 2015; Sabokbar et al., 2015; Sah et al., 2015; Yilmaz-Ersan et al., 2015). Although ewe and cow milks are widely used in the manufacture of different fermented milk products, little information is available on the antioxidative characteristics of kefir produced with these milk types. This study had 2 main aims. First, we determined the contents of vitamin E, $\beta$-carotene, and total phenolics, as well as total antioxidant capacity of kefir during different fermentation stages. Second, we investigated the varied roles of milk and starter culture type on kefir characteristics.

\section{MATERIALS AND METHODS}

\section{Kefir Grains and Inoculum Preparation}

Two types of starter cultures were used for manufacturing: traditional kefir grains (obtained from Department of Food Engineering, University of Uludag, Bursa, Turkey) and freeze-dried, direct vat set (DVS) culture (obtained from Danisco, Poznan, Poland). The DVS culture contains Lactococcus lactis, Lactococcus cremoris, Lactococcus diacetylactis, Candida kefir, and Saccharomyces unispora. For reactivation, the kefir grains were transferred 3 times into pasteurized milk, incubated at $25^{\circ} \mathrm{C}$ for $18 \mathrm{~h}$, separated from the milk, and washed with sterile distilled water. These active grains $(5 \%, \mathrm{wt} / \mathrm{vol})$ were used to inoculate the fermentation medium. Upon receipt, the DVS culture was added $2 \%$ ( $\mathrm{vol} / \mathrm{vol}$ ) directly to the fermentation medium.

\section{Kefir Production}

Raw cow and ewe milks were obtained from the Uludag University Dairy Farm (Bursa, Turkey), heated to $90^{\circ} \mathrm{C}$, and kept at that temperature for $10 \mathrm{~min}$. Then, the milks were cooled to the inoculation temperature $\left(25^{\circ} \mathrm{C}\right)$ and inoculated with active grains or DVS culture. After inoculation, milks were incubated at $25^{\circ} \mathrm{C}$ until the $\mathrm{pH}$ reached 4.60 to 4.70 . From each kefir batch, samples were collected at 4-h intervals during fermentation. At the end of the fermentation, the kefir grains were separated by use of a sterilized plastic sieve (2-mm pore size). After being transferred into 200-mL bottles, the kefir beverages were cooled to 4 to $6^{\circ} \mathrm{C}$ and stored at $4 \pm 1^{\circ} \mathrm{C}$ until analysis. The samples were analyzed on d 1, 7, 14, and 21 of cold storage. Cow $(\mathbf{C})$ and ewe $(\mathbf{E})$ milk kefir made using kefir grains (GR) and starter culture (SC) are designated C-GR, C-SC, E-GR, and E-SC, respectively. Two replications of all batches and 3 replications of the analyses were performed. The $\mathrm{pH}$ was monitored using a digital $\mathrm{pH}$ meter (Analyzer model 315i/SET, WTW, Weilheim, Germany) throughout fermentation.

\section{Chemicals}

2,2-Azinobis(3-ethylbenzothiazoline-6-sulfonic acid) di-ammonium salt (ABTS), 2,2-diphenyl-1-picrylhydrazyl (DPPH), 2,4,6-tripyridyl-2-triazine (TPTZ), Folin-Ciocalteu phenol reagent, potassium persulfate, gallic acid, tocopherol standards ( $\alpha$-tocopherol), HPLC-grade vitamin E and $\beta$-carotene were purchased from Sigma-Aldrich (St. Louis, MO); Trolox ([ $[ \pm]-6$-hydroxy-2,5,7,8-tetramethylchroman-2-carboxylic acid) was obtained from Aldrich Chemical Co. (Steinheim, Germany). All standard solutions were prepared in HPLC-grade methanol (Merck, Darmstadt, Germany).

\section{Extraction of Kefir Samples}

Kefir samples (2 g) were blended with $20 \mathrm{~mL}$ of aqueous methanolic solution $(70: 30 \%, \mathrm{vol} / \mathrm{vol})$ at room temperature in the dark for $4 \mathrm{~h}$ with magnetic stirring. The extracts were centrifuged at 1,420 $\times g$ for $10 \mathrm{~min}$ and filtered through qualitative filter paper (Whatman grade $2,8-\mu \mathrm{m}$ thickness); the supernatants were used for spectroscopic analysis.

Two grams of kefir was centrifuged and $5 \mathrm{~mL}$ of supernatant was saponified with $2 \mathrm{~mL}$ of an aqueous $\mathrm{KOH}(50 \%, \mathrm{vol} / \mathrm{vol})$ at $65^{\circ} \mathrm{C}$ for $30 \mathrm{~min}$ in a water bath at $40 \mathrm{kHz}$. After cooling on ice for $15 \mathrm{~min}, 4 \mathrm{~mL}(2 \times 2)$ of hexane and ethyl acetate solution $(80: 20 \%, \mathrm{vol} / \mathrm{vol})$ was added to extract vitamin E. The organic fractions $(3 \mathrm{~mL})$ were evaporated to dryness. Finally, the residue was dissolved in $1 \mathrm{~mL}$ of hexane for HPLC-diode array detection (DAD) analysis of vitamin $\mathrm{E}$. The kefir samples were extracted following the same method but without saponification for $\beta$-carotene analysis.

\section{Determination of Antioxidant Capacity}

ABTS Assay. Total antioxidant capacity of the samples was determined by using $\mathrm{ABTS}^{\bullet+}$ radical cation decolorization assay (Sahin et al., 2012). The $\mathrm{ABTS}^{\bullet+}$ radical stock solution was produced by re- 
acting $20 \mathrm{~m} M \mathrm{ABTS}^{\bullet+}$ with $2.45 \mathrm{~m} M$ potassium persulfate solution $(1: 1, \mathrm{vol} / \mathrm{vol})$ and storing in the dark at room temperature for 12 to $16 \mathrm{~h}$ before use. The ABTS $^{\bullet+}$ working solution was prepared by dilution of stock solution with ethanol at a ratio of 1:10 to obtain an absorbance of $0.7 \pm 0.02$ at $734 \mathrm{~nm}$. The ABTS ${ }^{\bullet+}$ decolorization assay procedure for kefir samples was as follows: $0.25 \mathrm{~mL}$ of kefir extract, $3.75 \mathrm{~mL}$ of ethanol, and $1 \mathrm{~mL}$ of the $\mathrm{ABTS}^{\bullet+}$ radical cation solution were mixed; the mixture was allowed to stand for 3 min at room temperature; and the absorbance at 734 $\mathrm{nm}$ was recorded by using a spectrophotometer (Varian Cary UV-Vis Spectrophotometer; Varian Inc., Palo Alto, CA) against a reagent blank. A standard curve was prepared using different concentrations of Trolox, and the results were expressed as milligrams of Trolox equivalents (TE) per $100 \mathrm{~mL}$ of sample.

DPPH Assay. The DPPH decolorization assay was executed as described by Sahin et al. (2012). First, 0.25 $\mathrm{mL}$ of extract and $0.18 \mathrm{~mL}$ of DPPH $\left(1 \times 10^{-3} M\right.$ stock solution) were mixed, and methanol was added to bring the final volume to $3 \mathrm{~mL}\left(6 \times 10^{-5} M\right)$ in a test tube. The absorbance readings were taken using a spectrophotometer (Varian Cary UV-Vis Spectrophotometer, Varian Inc.) at $515 \mathrm{~nm}$ against a reagent blank after being kept in dark for 30 min. Different concentrations of Trolox were used as standards for calibration, and the results were expressed as milligrams of TE per 100 $\mathrm{mL}$ of sample.

Ferric Reducing Antioxidant Power Assay. The ferric reducing antioxidant power (FRAP) assay was performed using the method of Benzie and Strain (1996) using a UV-Vis spectrophotometer (Varian Cary 50) with slight modifications. The method, using iron as a redox sensor, is based on the reduction of the $\mathrm{Fe}^{3+}$ TPTZ (ferrictripyridyltriazine) complex to the $\mathrm{Fe}^{2+}$ TPTZ at low $\mathrm{pH}$ in the presence of antioxidants. This reduction results in a blue color, which can be monitored by measuring the absorption change at $593 \mathrm{~nm}$. The working FRAP reagent was prepared by mixing 10 volumes of $1.0 \mathrm{M}$ acetate buffer, $\mathrm{pH} 3.6$, with 1 volume of $10 \mathrm{~m} M$ TPTZ in $40 \mathrm{mM} \mathrm{HCl}$ and with 1 volume of $20 \mathrm{mM} \mathrm{FeCl}{ }_{3}$. In a test tube, $0.25 \mathrm{~mL}$ of sample was mixed with $2.75 \mathrm{~mL}$ of the FRAP reagent and incubated at $37^{\circ} \mathrm{C}$ for $30 \mathrm{~min}$. The solution was then centrifuged at $1,050 \times g$ for $10 \mathrm{~min}$. The supernatant $(0.5 \mathrm{~mL})$ was mixed with $0.5 \mathrm{~mL}$ of distilled water and $0.1 \mathrm{~mL}$ of $0.1 \%$ (wt/vol) $\mathrm{FeCl}_{3}$. Absorbance was measured after 8 min. A standard curve was prepared using different concentrations of $\mathrm{FeSO}_{4} \cdot 7 \mathrm{H}_{2} \mathrm{O}(100-1,000 \mu M)$. The antioxidant efficiency of the sample solution was calculated with reference to the standard curve given by a $\mathrm{Fe}^{2+}$ solution of known concentration. The results were expressed as milligrams of TE per $100 \mathrm{~mL}$ of sample.

\section{Determination of Total Phenolic Content}

The total phenolic content (TPC) was determined by Folin-Ciocalteu method as described by Sahin et al. (2013). The absorbance was measured using a spectrophotometer (Varian Cary UV-Vis spectrophotometer) at $750 \mathrm{~nm}$ against a reagent blank after $30 \mathrm{~min}$ at room temperature. A standard calibration curve was plotted using different concentrations of gallic acid and TPC was expressed in milligrams of gallic acid equivalents (GAE) per $100 \mathrm{~mL}$ of sample.

\section{Determination of Vitamin $E$ and $\beta$-Carotene Contents}

Vitamin $\mathrm{E}$ and $\beta$-carotene contents in kefir samples were determined by HPLC-diode array detection (Agilent 1200 HPLC System, Agilent Technologies, Waldbronn, Germany) analysis. The HPLC system consisted of a vacuum degasser, binary pump, autosampler, and YMC Carotenoid C30 column $(4.6 \times 250 \mathrm{~mm}$ internal diameter, $5-\mu \mathrm{m}$ film thickness) column. The mobile phase was $95 \%$ methanol and $0.05 \%$ triethylamine in water (solvent A) and methyl tert-butyl ether (solvent B). The gradient profile of the mobile phase was as follows: $0-5$ min $5 \% \mathrm{~B}, 15-20 \mathrm{~min} 20 \% \mathrm{~B}, 20-30 \mathrm{~min}$ $30 \%$ B, 30-40 min $40 \%$ B, 40-75 min $75 \%$ B, 40-45 min $5 \% \mathrm{~B}$; the total run time was $45 \mathrm{~min}$. The column was equilibrated for $10 \mathrm{~min}$ before each analysis at $25^{\circ} \mathrm{C}$. The flow rate was $1.0 \mathrm{~mL} / \mathrm{min}$ and injection volume was $20 \mu \mathrm{L}$. The monitoring wavelength was $225 \mathrm{~nm}$ for vitamin $\mathrm{E}$ and $450 \mathrm{~nm}$ for $\beta$-carotene. The peaks were identified and quantified based on comparison of retention times of standard solutions.

\section{Statistical Analysis}

Statistical analyses was performed with Minitab 13.0 for Windows (Minitab Inc., State College, PA), and the data were compared using ANOVA at 1 and $5 \%$ significance levels. The results are presented as means \pm standard errors. Differences between means of the kefir samples were controlled using the least significant difference multiple range test, as the level of significant difference was used to determine the effect of fermentation and storage time on the antioxidant properties. Hierarchical cluster analysis, which gives intuitive similarity relationships between one sample and the entire data set, was used to discriminate kefir samples with different culture and milk types and the antioxidant properties based on their similarities with respect to predetermined selection criterion. Two-way clustering and Ward's linkage method were performed for clustering (JMP Software Version 12, SAS Institute Inc., Cary, NC). 
Table 1. Total antioxidant capacity (TAC) and total phenolic content (TPC) of raw and heat-treated cow and ewe milks

\begin{tabular}{|c|c|c|c|c|}
\hline \multirow[b]{2}{*}{ Item } & \multicolumn{2}{|c|}{ Ewe milk } & \multicolumn{2}{|c|}{ Cow milk } \\
\hline & Raw & Heat-treated & Raw & Heat-treated \\
\hline \multicolumn{5}{|c|}{ TAC method ${ }^{1}$} \\
\hline DPPH & 8.70 & 5.03 & 3.14 & 2.66 \\
\hline ABTS & 33.18 & 24.13 & 21.48 & 48.60 \\
\hline FRAP & 5.82 & 6.43 & 1.41 & 6.15 \\
\hline $\mathrm{TPC}^{2}$ & 121.63 & 115.82 & 68.91 & 152.14 \\
\hline
\end{tabular}

${ }^{1} \mathrm{DPPH}=2,2$-diphenyl-1-picrylhydrazyl assay; ABTS $=2$ 2,2-azinobis(3-ethylbenzothiazoline-6-sulfonic acid) assay; FRAP = ferric reducing antioxidant power assay; results were expressed as milligrams of Trolox equivalents (TE) per $100 \mathrm{~mL}$ of sample.

${ }^{2}$ Expressed in milligrams of gallic acid equivalents (GAE) per $100 \mathrm{~mL}$.

\section{RESULTS AND DISCUSSION}

\section{Acidification Kinetics}

The manner of $\mathrm{pH}$ decline is an important parameter to evaluate the fermentation capacity of starter microorganisms used in dairy products. The activity and growth rate of starter cultures are known to vary with lactose and protein contents of milk, fermentation conditions, and the type of milk (Rogelj and Perko, 1998). Figure 1 presents the variation in $\mathrm{pH}$ values of kefir samples during fermentation as well as the average acidification time needed to reach a $\mathrm{pH}$ of 4.60 to 4.70. We detected significant differences in $\mathrm{pH}$ values among the samples depending on the culture and milk type used $(P<0.01)$. At the beginning of the acidification process, the $\mathrm{pH}$ values of kefirs were similar, ranging from 6.46 to 6.20 , and then decreased gradually throughout the acidification period to reach the target $\mathrm{pH}$. The final $\mathrm{pH}$ was higher in kefir made using kefir grains, independent of milk type, indicating that the commercial starter culture was more effective in decreasing the $\mathrm{pH}$ to the target. The final $\mathrm{pH}$ of all kefirs averaged 4.6, illustrating the effective process control obtained during acidification. Time to reach the desired $\mathrm{pH}$ was $4 \mathrm{~h}$ for C-SC, whereas it was almost $24 \mathrm{~h}$ for E-SC. In the samples inoculated with grains, $\mathrm{pH}$ decreased to 4.74 after $12 \mathrm{~h}$ of the fermentation for E-GR and to 4.57 during $24 \mathrm{~h}$ of fermentation for C-GR. The acidification time observed in the present study was similar to that reported by Wszolek et al. (2001), who investigated the properties of kefir made from cow, goat, and ewe milks with different starter cultures. In the present study, variations in $\mathrm{pH}$ of the kefir samples were due to the different buffering capacities of the milks and differential microbial populations during fermentation. The largest decrease in $\mathrm{pH}$ was observed for kefir samples made with grains because they have higher metabolic activity than commercial starter culture.

\section{Antioxidant Capacity of Milk Used for Kefir Manufacture}

The efficiency of antioxidants in biological systems may differ, thus, various methods based on different principles should be used to evaluate TAC. There is increasing interest in measuring total antioxidant activity rather than simply the contents of different antioxidants. The total antioxidant capacity (TAC) of raw cow and ewe milks used for kefir manufacture was evaluated by 3 methods in the current study: DPPH radical scavenging, ABTS radical scavenging, and ferric reducing antioxidant potential. The antioxidant capacity of raw and heated milks showed significant differences in relation to the method of estimation, as shown in Table 1.

Phenolic compounds are present both in soluble form and combined with proteins in milk. The temperature and duration of heat treatment, $\mathrm{pH}$, protein type and concentration, and the type and structure of phenolic compounds may cause reversible or permanent breakdown of the protein-polyphenolic bonds (O'Connella and Fox, 2001; Rashidinejad et al., 2015). In the current study, milks were heated to $90^{\circ} \mathrm{C}$ for pasteurization before their antioxidant capacity was tested. The heat-

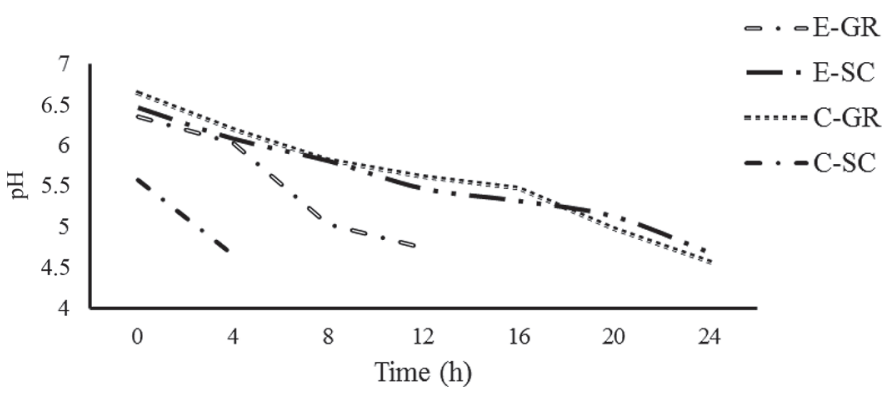

Figure 1. Changes of $\mathrm{pH}$ of kefir samples during fermentation. $\mathrm{C}-\mathrm{GR}=$ cow milk kefir made using kefir grains; C-SC = cow milk kefir made using starter culture; E-GR = ewe milk kefir made using kefir grains; $\mathrm{E}-\mathrm{SC}=$ ewe milk kefir made using starter culture. 
ing process was effective on TAC and TPC in both cow and ewe milk (Table 1).

The DPPH, ABTS, and TPC values were lower for heat-treated ewe milk than for raw milk, whereas the FRAP value was higher. The TPC values of ewe milk decreased during heat treatment but increased for cow milk, indicating the instability of phenolics to heat, depending on the differences of biologically active components present in both milk species. Although heat treatment decreased the DPPH value in cow milk, it resulted in higher ABTS, FRAP, and TPC values. Calligaris et al. (2004) stated that the reducing properties of milk were strongly affected by heating; heat treatment could increase its pro-oxidant activity, probably as a consequence of both the loss of natural antioxidants and the formation of novel oxidative molecules in the early stages of the Maillard reaction. However, only the application of severe heat treatments, associated with the formation of brown melanoidins, allowed a recovery, and even a possible increase in antioxidant properties. In addition to their nutritive ingredients, dairy products such as milk, yogurt, cheese, and kefir contain antioxidative factors (Songisepp et al., 2004; Liu et al., 2005; Aloglu and Oner, 2011). Milk proteins, such as caseins, $\beta$-LG, $\alpha$-LA, immunoglobulins, lactoferrin, and serum albumin, can exert their antioxidant activity directly or after hydrolysis to different peptides by proteolytic enzymes (Lindmark-Månsson and Akesson, 2000; Virtanen et al., 2007).

The ABTS assay gave higher values than the DPPH and FRAP methods for ewe milk, because some milk components such as cysteine, glutathione, and protein sulfhydryls, depending on the AA sequence, can scavenge $\mathrm{ABTS}^{\bullet+}$ radicals (Cao and Prior, 1998; Suetsuna et al., 2000; Rival et al., 2001), in agreement with Chen et al. (2003).

Milk antioxidant components should be considered as lipophilic and hydrophilic. Vitamin E and carotenoids contribute to antioxidant activity in the lipophilic phase, whereas ascorbic acid contributes in the hydrophilic phase (Pulido et al., 2003). Therefore, differences in antioxidative capacity between cow and ewe milks could be explained by their relative contents of fat, protein, vitamin, minerals, phenolic compounds, antioxidative enzymes, and fatty acid and AA compositions. The TPC values of ewe milk decreased during heat treatment but those of cow milk increased (Table 1). In many studies, the effects of heat treatment on TPC in foods are contradictory. Some researchers reported an increase in the phenolic content, whereas others observed a decrease. Ertan et al. (2017) stated that heat treatment conditions and sample matrix could be responsible for these contradictory results.

\section{Antioxidant Capacity of Kefir During Fermentation}

The TPC and antioxidative capacity values of kefir samples showed significant variations during fermentation, probably due to inhibition of enzymes of the microorganisms present in kefir grains and commercial starter, which were activated at the initial stages of fermentation (Figures 2 and 3). The TPC data were comparable to previous findings that reported values between 74.67 and $148.84 \mathrm{mg}$ of GAE/100 mL for ewe kefir and between 66.70 and $176.87 \mathrm{mg}$ of GAE/100 mL for cow kefir. The vitamin $\mathrm{E}$ and $\beta$-carotene contents of the kefir samples during fermentation showed no detectable significant differences, and therefore, vitamin $\mathrm{E}$ and B-carotene values were not considered for TAC.

We detected significant differences by kefir type and fermentation time for TAC values $(P<0.01)$. The values for DPPH throughout fermentation in E-GR and E-CS were 1.68 and $9.05 \mathrm{mg}$ of $\mathrm{TE} / 100 \mathrm{~mL}$, respectively, whereas $\mathrm{DPPH}$ values in $\mathrm{C}-\mathrm{GR}$ and $\mathrm{C}-\mathrm{CS}$ were 3.99 and $9.57 \mathrm{mg}$ of TE/100 mL. The average ABTS scavenging capacities in E-GR and E-CS were 11.34 and $32.93 \mathrm{mg}$ of TE/100 mL and in C-GR and C-CS were 10.25 and $22.44 \mathrm{mg}$ of $\mathrm{TE} / 100 \mathrm{~mL}$, respectively. The average FRAP values of ewe milk kefir by grains and commercial starter culture were 5.09 and $15.27 \mathrm{mg}$ of TE/100 mL, whereas for cow milk kefir they were 145 and $12.34 \mathrm{mg}$ of TE/100 mL, respectively (Figure 3a-d).

After the addition of kefir grains to the milks at $0 \mathrm{~h}$ of fermentation, ABTS values were highest of all TAC assays. At the end of fermentation, DPPH and ABTS values of E-GR kefir samples had decreased significantly $(P<0.01)$, whereas FRAP values had increased $(P<0.01)$. As shown in Figure 3a, the ABTS assay for E-GR sample had greater values than other TAC methods. The DPPH assay is a reproducible and simple method in which the reduction in the concentration of this stable radical is measured by decolorization with an antioxidant component present in milk such as AA including cysteine, tocopherol, and glutathione peroxidase. This decolorization is stoichiometric with respect to the number of electrons captured (Nishino et al., 2000). This assay was used by Sabokbar et al. (2015), who stated that fermentation with kefir grains had a positive influence on scavenging activity of DPPH radical.

The ABTS and FRAP values of E-SC kefir were highest after $8 \mathrm{~h}$ of fermentation (Figure $3 \mathrm{~b}$ ). The variations in antioxidative capacity of kefir samples during fermentation might be the result of differences of microorganisms and their activity in grains and commercial starter culture. Because kefir has high protein content, 


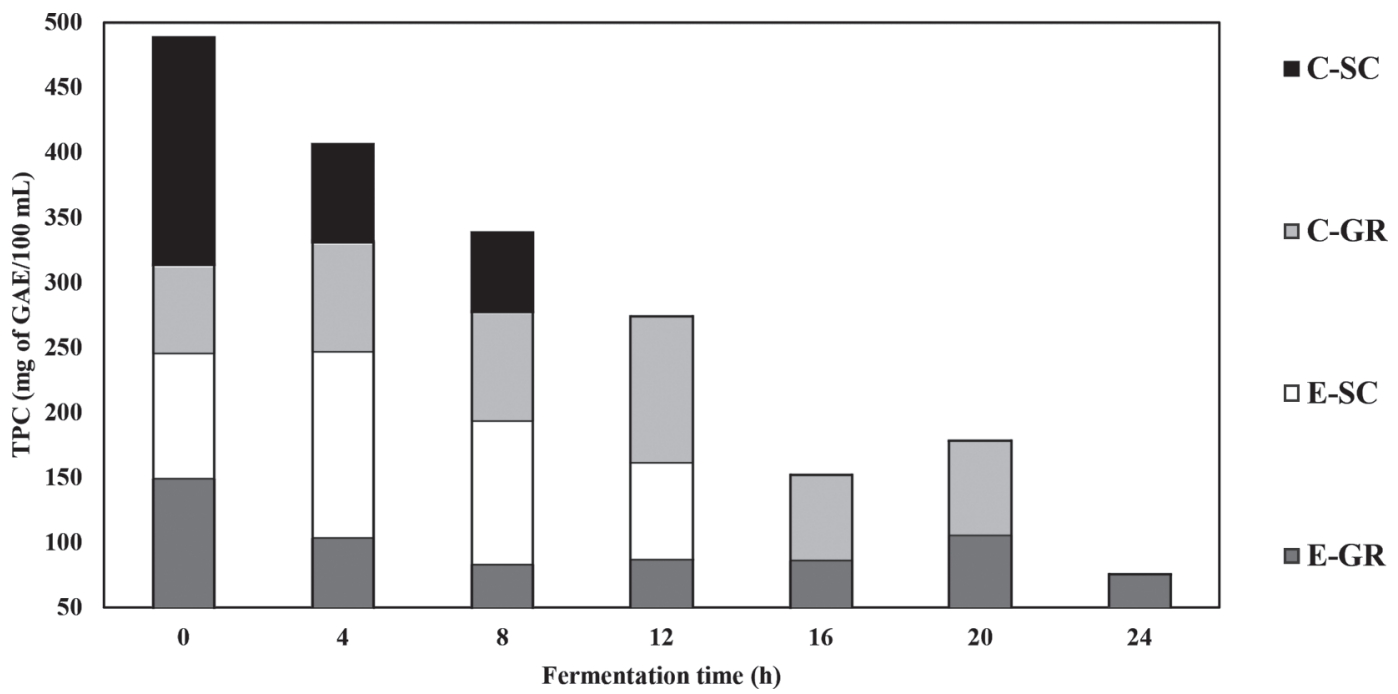

Figure 2. Changes of total phenolic content [TPC; in mg of gallic acid equivalents (GAE) per $100 \mathrm{~mL}$ ) of kefir samples during fermentation. $\mathrm{C}-\mathrm{GR}=$ cow milk kefir made using kefir grains; C-SC = cow milk kefir made using starter culture; E-GR = ewe milk kefir made using kefir grains; E-SC = ewe milk kefir made using starter culture.

the free AA and oligopeptides formed by microbial proteases during fermentation could also account for antioxidant activity. The synergistic effect of phenolics with other components present could contribute to the overall observed antioxidant capacity. Therefore, the fermentation period is critical to ensure optimal breaking down of compound linkages but not permit free compounds to be used as substrates for microbial growth (Ehsan et al., 2010).

The antioxidative capacity values of C-GR and C-SC samples are shown in Figure 3c and 3d. We detected significant differences $(P<0.01)$ in DPPH, ABTS, and FRAP values throughout fermentation. The ABTS and FRAP values in C-GR were highest at $12 \mathrm{~h}$ of the fermentation. This might be attributed to the population and metabolites formed by the activity of complex microorganisms present in the grains and bacterial culture. The FRAP values increased progressively during the first $8 \mathrm{~h}$ of fermentation for E-GR, E-SC, and C-GR samples in contrast to the decrease in $\mathrm{pH}$, which allowed us to assess the color change by reduction of ferric ion to ferrous at low $\mathrm{pH}$. The FRAP values of E-GR were highest at $24 \mathrm{~h}$ of fermentation. Bioactive peptides in milk, the lactic acid bacteria present, and their $\mathrm{Fe}^{2+}$ chelating ability might contribute to the high reducing activity of the E-GR sample. Lin and Yen (1999) demonstrated that Lactobacillus acidophilus, Lactobacillus delbrueckii ssp. bulgaricus, Streptococcus thermophilus, and Bifidobacterium longum had chelating ability due to intracellular chelators such as penicillamine. These chelators could capture metal ions that catalyze oxidation reactions.
Kefir grains and commercial culture consist of different species of lactic acid bacteria, acetic acid bacteria, yeasts, and filamentous molds in varying numbers. Because the phenomenon of associations of microbial populations in the grains has not been completely elucidated, commercial cultures containing various lactic acid bacteria or yeast species isolated from kefir grains are used to standardize kefir production. However, kefir manufactured with a pure culture is differentiated from that manufactured with kefir grains by sensorial and chemical attributes, depending on the activity of microorganisms present, as some species are absent in commercial cultures (Wszolek et al., 2001; de Oliveira Leite et al., 2013; Arslan, 2015; Prado et al., 2015).

The instability of antioxidant activity observed in kefir samples might be related to various factors such as the type of milk, chemical composition, processing conditions, starter culture type/amount, microbial population of the grains, types of enzymes in starter culture, hydrolysis of proteins, polarity, and ability to donate atoms and electrons of antioxidant biofactors (Sun et al., 2009; Perna et al., 2013). Some natural bioactive components in kefir exhibit a relatively slow scavenging potential, because large peptides and proteins hydrolyze slowly, and thus display a lower antioxidant activity. Furthermore, low-molecular-weight casein hydrolysates could have strong radical scavenging activities due to differences in characteristics of the starter culture used (Kim et al., 2007; Sah et al., 2015). Virtanen et al. (2007) noted that antioxidant activity in fermented products could be attributed to the development of proteolysis. 


\section{Antioxidant Capacity of Kefir During Storage}

It is known that kefir has antioxidant components such as proteins, phenolics, vitamins; however, to our knowledge, there is no comparative study on antioxidant properties of kefir made from cow and ewe milk with kefir grains and commercial starter culture. The

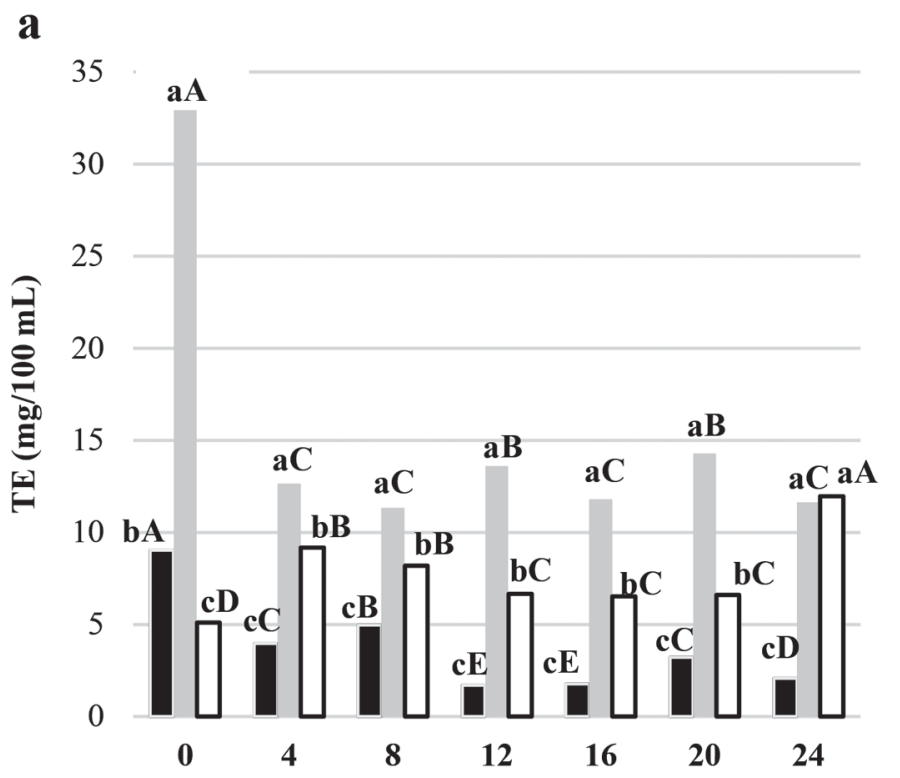

Fermentation time (h)

c

$$
25
$$

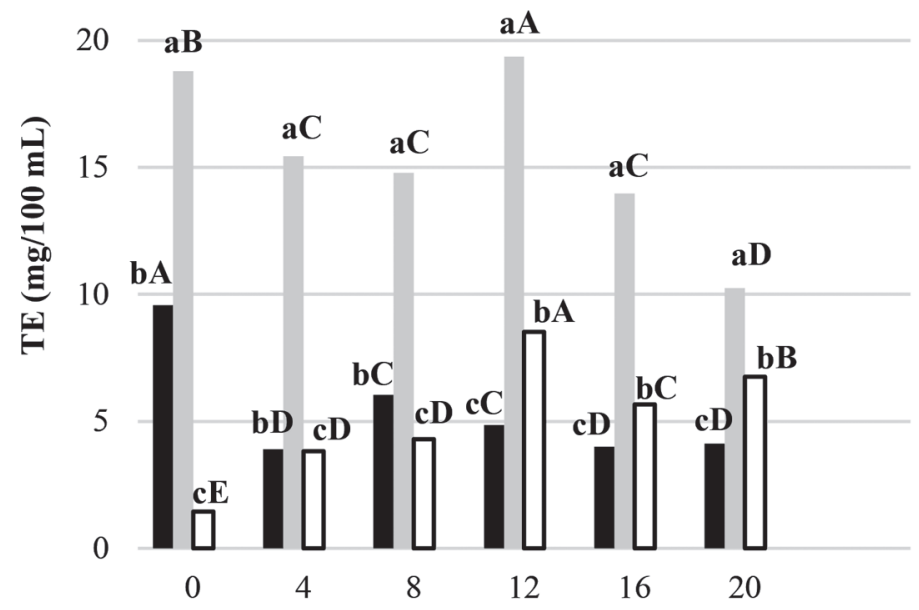

Fermentation time (h)
TAC results for kefir samples as a function of storage time are presented in Table 2. The differences between the results of all TAC methods for all kefir samples were statistically significant $(P<0.01)$. The highest antioxidant capacity values were observed using the ABTS assay and lowest for the DPPH assay. In terms of antioxidative capacities, kefir made from ewe milk had

b

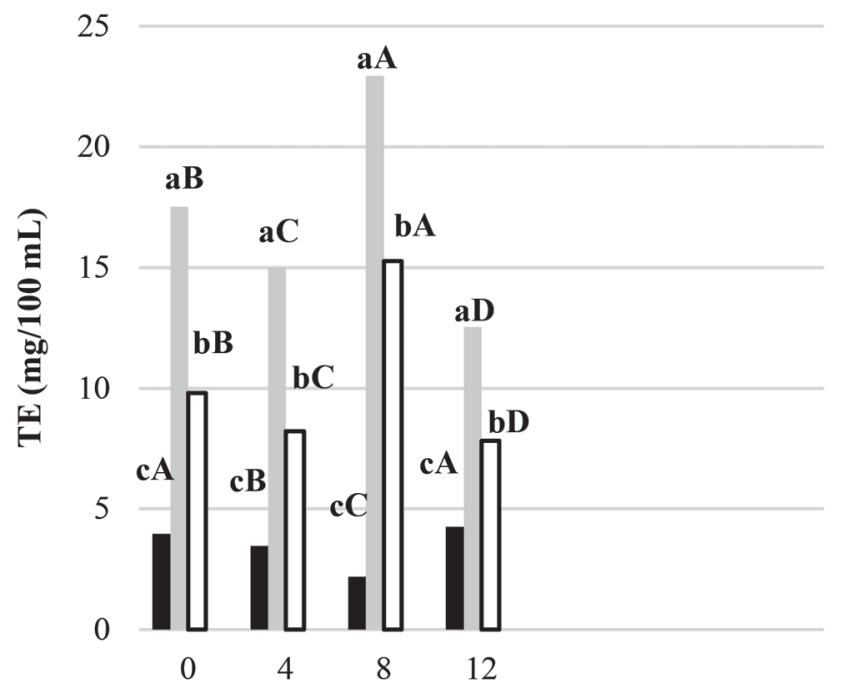

Fermentation time (h)

d

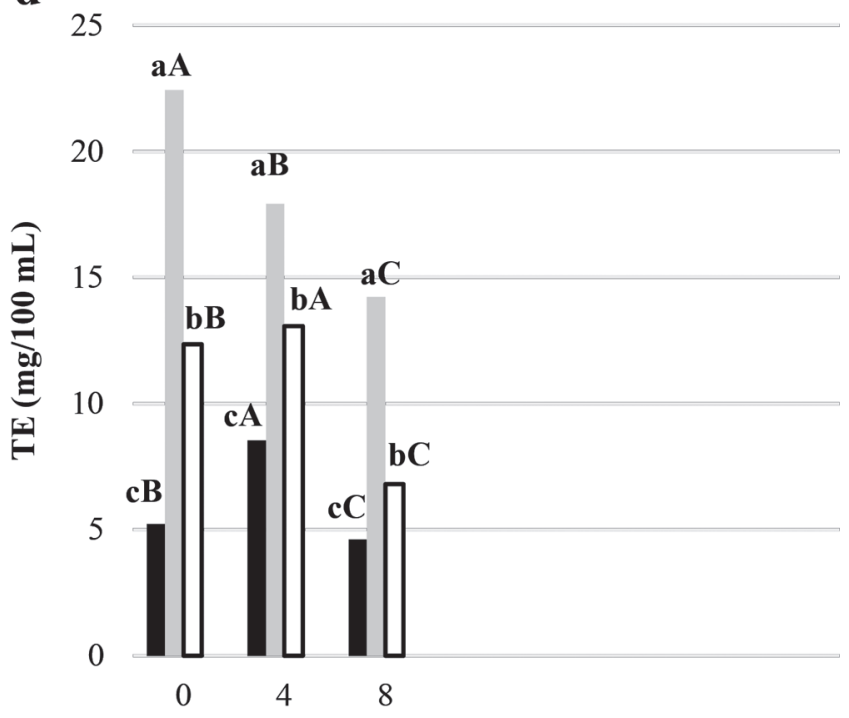

Fermentation time (h)

Figure 3. Changes of antioxidative capacity of ewe milk kefir made using kefir grains (E-GR; a), ewe milk kefir made using starter culture (E-SC; b), cow milk kefir made using kefir grains (C-GR; c), and cow milk kefir made using starter culture (C-SC; d) during fermentation. Antioxidant capacity was measured using the 2,2-diphenyl-1-picrylhydrazyl (DPPH, black bars), 2,2-azinobis(3-ethylbenzothiazoline-6-sulfonic acid) (ABTS, gray bars), and ferric reducing antioxidant power (FRAP, white bars) assays. Different lowercase letters (a-c) indicate significant differences between assays $(P<0.01)$; different uppercase letters $(\mathrm{A}-\mathrm{E})$ indicate significant differences between means for fermentation time $(P<0.01)$. 
higher levels than kefir made from cow milk, and kefir samples fermented by grain gave higher antioxidant capacity for DPPH, and the highest ABTS results were obtained in kefir samples fermented by starter culture at the end of storage. In general, differences in antioxidative capacity observed among kefir samples with grains and pure culture could be due to the specific AA sequence of the milk proteins or the lipid contents of milks, which affects the reactivity of lipid-soluble antioxidants and fat globule membrane proteins (Chen et al., 2003). More likely, the TAC values of kefir samples represent a complex mixture of numerous compounds with antioxidant activities functioning via different chemical reactions.

The DPPH values increased notably in ewe kefir samples during refrigerated storage $(P<0.01)$. This might be explained by proteolysis and increased organic acid content as a result of post-acidification during storage (Lourens-Hattingh and Viljoen, 2001; Correia et al.,
2004). Maximum levels of the DPPH values were observed on d 7 of storage for cow kefir samples. Extended storage to $21 \mathrm{~d}$ resulted in a decrease in $\mathrm{DPPH}$ value relative to that at $\mathrm{d}$ 7. Shori and Baba (2013) reported that DPPH scavenging activity was highest on $\mathrm{d} 7$ and 14 for plain yogurt, after which values decreased until d 28, to levels below that on d 1 of storage. Similarly, Halah and Mehanna (2011) reported that DPPH values of milk fermented by Lactobacillus rhamnosus declined after $7 \mathrm{~d}$ of storage.

A significant increase in ABTS value was observed until d 14 of storage for E-GR, E-SC, and C-SC samples, which decreased thereafter until d 21. Among the samples, E-SC exhibited the highest $\mathrm{ABTS}^{\bullet+}$ inhibition rate (Table 2). Our results were in agreement with those reported by Perna et al. (2013), who observed a significant increase in ABTS until d 15 in yogurt made from cow milk. Gupta et al. (2009) reported that ABTS and DPPH values for Cheddar cheese manufactured

Table 2. Changes in antioxidant capacity, total phenolic content, and contents of vitamin E and $\beta$-carotene in kefir samples during storage (means $\pm \mathrm{SE})$

\begin{tabular}{|c|c|c|c|c|c|}
\hline Item $^{1}$ & $\begin{array}{l}\text { Storage } \\
\text { time (d) }\end{array}$ & \multicolumn{4}{|c|}{ Kefir sample ${ }^{2}$} \\
\hline $\begin{array}{l}\mathrm{DPPH} \\
(\mathrm{mg} \text { of } \mathrm{TE} / 100 \mathrm{~mL})\end{array}$ & $\begin{array}{l}1 \\
7 \\
14 \\
21\end{array}$ & $\begin{array}{l}3.03 \pm 1.055^{\mathrm{c}, \mathrm{C}} \\
2.15 \pm 0.018^{\mathrm{c}, \mathrm{D}} \\
3.76 \pm 0.034^{\mathrm{b}, \mathrm{B}} \\
4.84 \pm 0.000^{\mathrm{b}, \mathrm{A}}\end{array}$ & $\begin{array}{l}6.25 \pm 0.010^{\mathrm{a}, \mathrm{B}} \\
6.76 \pm 0.071^{\mathrm{a}, \mathrm{A}} \\
5.59 \pm 0.003^{\mathrm{a}, \mathrm{C}} \\
5.41 \pm 0.141^{\mathrm{a}, \mathrm{C}}\end{array}$ & $\begin{array}{l}2.10 \pm 0.004^{\mathrm{d}, \mathrm{C}} \\
1.86 \pm 0.006^{\mathrm{d}, \mathrm{D}} \\
2.34 \pm 0.051^{\mathrm{d}, \mathrm{B}} \\
4.19 \pm 0.008^{\mathrm{c}, \mathrm{A}}\end{array}$ & $\begin{array}{l}5.97 \pm 0.016^{\mathrm{b}, \mathrm{B}} \\
6.55 \pm 0.019^{\mathrm{b}, \mathrm{A}} \\
2.79 \pm 0.006^{\mathrm{c}, \mathrm{D}} \\
3.40 \pm 0.141^{\mathrm{d}, \mathrm{C}}\end{array}$ \\
\hline $\begin{array}{l}\text { FRAP } \\
(\mathrm{mg} \text { of TE/100 mL) }\end{array}$ & $\begin{array}{l}1 \\
7 \\
14 \\
21\end{array}$ & $\begin{array}{r}11.68 \pm 0.007^{\mathrm{a}, \mathrm{A}} \\
7.10 \pm 0.141^{\mathrm{a}, \mathrm{D}} \\
8.41 \pm 0.007^{\mathrm{a}, \mathrm{C}} \\
9.97 \pm 0.000^{\mathrm{a}, \mathrm{B}}\end{array}$ & $\begin{array}{l}7.19 \pm 0.141^{\mathrm{c}, \mathrm{A}} \\
7.16 \pm 0.156^{\mathrm{a}, \mathrm{A}} \\
6.68 \pm 0.007^{\mathrm{c}, \mathrm{B}} \\
6.40 \pm 0.014^{\mathrm{c}, \mathrm{B}}\end{array}$ & $\begin{array}{l}5.05 \pm 0.014^{\mathrm{d}, \mathrm{B}} \\
5.14 \pm 0.006^{\mathrm{b}, \mathrm{B}} \\
7.53 \pm 0.240^{\mathrm{b}, \mathrm{A}} \\
8.10 \pm 0.141^{\mathrm{b}, \mathrm{A}}\end{array}$ & $\begin{array}{l}8.47 \pm 0.240^{\mathrm{b}, \mathrm{A}} \\
6.81 \pm 0.141^{\mathrm{a}, \mathrm{B}} \\
6.86 \pm 0.141^{\mathrm{c}, \mathrm{B}} \\
6.04 \pm 0.062^{\mathrm{c}, \mathrm{C}}\end{array}$ \\
\hline $\begin{array}{l}\text { Vitamin E } \\
(\mathrm{mg} / 100 \mathrm{~g})\end{array}$ & $\begin{array}{l}1 \\
7 \\
14 \\
21\end{array}$ & $\begin{array}{l}0.037 \pm 0.0001^{\mathrm{b}, \mathrm{D}} \\
0.051 \pm 0.0009^{\mathrm{b}, \mathrm{B}} \\
0.084 \pm 0.0002^{\mathrm{b}, \mathrm{A}} \\
0.040 \pm 0.0001^{\mathrm{a}, \mathrm{C}}\end{array}$ & $\begin{array}{l}0.025 \pm 0.0002^{\mathrm{c}, \mathrm{A}} \\
0.014 \pm 0.0000^{\mathrm{c}, \mathrm{C}} \\
0.008 \pm 0.0001^{\mathrm{c}, \mathrm{D}} \\
0.017 \pm 0.0002^{\mathrm{d}, \mathrm{B}}\end{array}$ & $\begin{array}{l}0.045 \pm 0.0000^{\mathrm{a}, \mathrm{C}} \\
0.094 \pm 0.0004^{\mathrm{a}, \mathrm{B}} \\
0.121 \pm 0.0001^{\mathrm{a}, \mathrm{A}} \\
0.032 \pm 0.0000^{\mathrm{b}, \mathrm{D}}\end{array}$ & $\begin{array}{l}0.018 \pm 0.0001^{\mathrm{d}, \mathrm{C}} \\
0.015 \pm 0.0003^{\mathrm{c}, \mathrm{D}} \\
0.084 \pm 0.0000^{\mathrm{b}, \mathrm{A}} \\
0.022 \pm 0.0002^{\mathrm{c}, \mathrm{B}}\end{array}$ \\
\hline $\begin{array}{l}\beta \text {-Carotene } \\
(\mathrm{mg} / 100 \mathrm{~g})\end{array}$ & $\begin{array}{l}1 \\
7 \\
14 \\
21\end{array}$ & $\begin{array}{l}0.004 \pm 0.0000^{\mathrm{b}, \mathrm{A}} \\
0.002 \pm 0.0001^{\mathrm{b}, \mathrm{C}} \\
0.003 \pm 0.0001^{\mathrm{c}, \mathrm{B}} \\
0.003 \pm 0.0000^{\mathrm{b}, \mathrm{B}}\end{array}$ & $\begin{array}{l}0.005 \pm 0.0005^{\mathrm{a}, \mathrm{A}} \\
0.004 \pm 0.0002^{\mathrm{a}, \mathrm{A}} \\
0.003 \pm 0.0000^{\mathrm{b}, \mathrm{B}} \\
0.003 \pm 0.0001^{\mathrm{b}, \mathrm{B}}\end{array}$ & $\begin{array}{l}0.003 \pm 0.0004^{\mathrm{c}, \mathrm{B}} \\
0.004 \pm 0.0000^{\mathrm{a}, \mathrm{A}} \\
0.004 \pm 0.0001^{\mathrm{a}, \mathrm{A}} \\
0.004 \pm 0.0002^{\mathrm{a}, \mathrm{A}}\end{array}$ & $\begin{array}{l}0.002 \pm 0.0000^{\mathrm{d}, \mathrm{A}} \\
0.002 \pm 0.0004^{\mathrm{b}, \mathrm{A}} \\
0.002 \pm 0.0001^{\mathrm{d}, \mathrm{A}} \\
0.002 \pm 0.0002^{\mathrm{c}, \mathrm{A}}\end{array}$ \\
\hline
\end{tabular}

\footnotetext{
${ }^{\mathrm{a} d}$ Different lowercase superscripts in the same row indicate significant differences between means for kefir samples $(P<0.01)$.

${ }^{\mathrm{A}-\mathrm{D}}$ Different uppercase superscripts in the same column indicate significant differences between means for storage time $(P<0.01)$.

${ }^{1} \mathrm{DPPH}=2,2$-diphenyl-1-picrylhydrazyl [in $\mathrm{mg}$ of Trolox equivalents (TE) per $100 \mathrm{~mL}$ ]; ABTS = 2,2-azinobis(3-ethylbenzothiazoline-6-sulfonic acid); FRAP = ferric reducing antioxidant power assay; TPC = total phenolic content [in $\mathrm{mg}$ of gallic acid equivalents (GAE) per $100 \mathrm{~mL}$ ].

${ }^{2} \mathrm{E}-\mathrm{GR}=$ ewe milk kefir made using kefir grains; C-GR = cow milk kefir made using kefir grains; E-SC = ewe milk kefir made using starter culture; C-SC = cow milk kefir made using starter culture.
} 
with Lactobacillus casei ssp. casei 300 and Lactobacillus paracasei ssp. paracasei 22 increased during the first 4 mo of ripening and decreased significantly thereafter.

We detected significant changes in antioxidant activity evaluated by FRAP assay during storage. The highest FRAP values were determined for E-GR, C-GR, and C-SC at the beginning of storage, whereas an increase in FRAP during storage was recorded in the E-SC sample. The results were in agreement with the study of Najgebouer-Lejko et al. (2014).

After $21 \mathrm{~d}$ of storage, the highest antioxidative capacity was recorded in C-GR samples for DPPH, in E-SC samples for ABTS, and in E-GR samples for FRAP (Table 2). The assays used in the present study are relatively simple, rapid, widely used, and applicable to both hydrophilic and lipophilic antioxidant systems. However, they are based on different compounds having differing antioxidant activities. In addition, differences in antioxidative capacity of kefir samples might be related partly to their proteolysis type, the resultant AA composition, and their vitamin and fat contents, which influence the solubilization and concentration of carotenoids.

Mean TPC increased significantly $(P<0.01$, Table 2) throughout storage. The TPC in cow and ewe kefir samples ranged between 59.09 and $85.69 \mathrm{mg}$ of GAE/100 mL and 77.74 and $84.79 \mathrm{mg}$ of GAE/100 $\mathrm{mL}$, respectively (Table 2). The addition of commercial starter culture to kefir milk resulted in slightly higher TPC values than when using kefir grains. On d 7, TPC values for both C-SC and C-GR declined but then increased thereafter until $d 21$. These variations in TPC for C-SC samples might be explained by further breakdown of phenolic compounds by enzymatic activity of starter culture during storage (Dalling, 1986). In the present study, ewe kefir samples had higher TPC than cow samples. Similar to cow kefir samples, TPC values of E-SC were higher than those of E-GR during storage. A possible explanation for higher TPC is related to metabolic activities of commercial starter culture, which can hydrolyze complex phenolic compounds into free phenolics (Sabokbar et al., 2015). Further studies are required to characterize the polyphenolic content in ewe milk, which may be responsible for the elevated TPC.

Table 2 shows the contents of vitamin $\mathrm{E}$ and $\beta$-carotene, which, as fat-soluble antioxidants, may contribute to dietary antioxidant intake from milk. The vitamin $\mathrm{E}$ contents of kefir samples ranged from 0.008 to $0.121 \mathrm{mg} / 100 \mathrm{~g}$, whereas $\beta$-carotene contents ranged from 0.002 to $0.005 \mathrm{mg} / 100 \mathrm{~g}$. In general, a significantly higher content of vitamin $\mathrm{E}$ was found in ewe milk kefirs than in cow milk kefirs $(P<0.01)$. No significant variations were found for $\beta$-carotene in all kefir samples throughout storage.

\section{Cluster Analysis}

Cluster analysis was performed using the hierarchical clustering method with Ward's linkage and 2-way clustering based on similar antioxidant capacities (evaluated by measuring scavenging capacity for DPPH, ABTS, and FRAP), TPC, and vitamin $\mathrm{E}$ and $\beta$-carotene contents on the first day of storage at $4^{\circ} \mathrm{C}$ (Figure 4). Four kefir samples were grouped into 3 clusters based on the mean values generated from the unweighted pair group mean average method of analysis, and all analysis parameters were grouped into 2 clusters. The results showed that C-GR samples were very similar to both E-GR and E-SC on the measured variables compared with the C-SC kefir. However, 2 clusters were observed in the case of antioxidant properties. The DPPH and

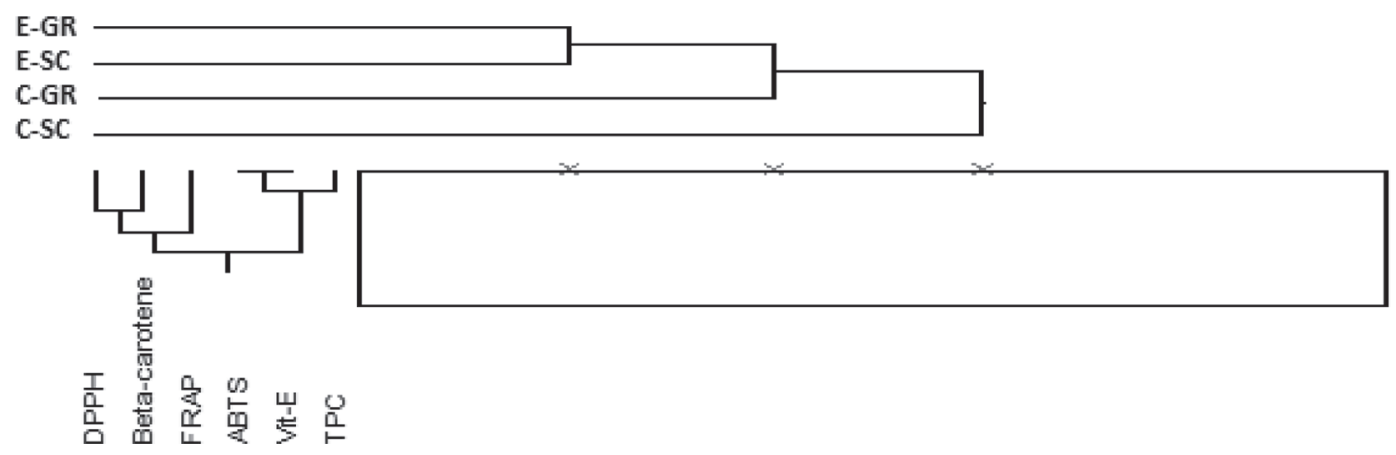

Figure 4. Cluster analysis of kefir samples. C-GR = cow milk kefir made using kefir grains; C-SC = cow milk kefir made using starter culture; $\mathrm{E}-\mathrm{GR}=$ ewe milk kefir made using kefir grains; E-SC = ewe milk kefir made using starter culture. The box indicates the distance of DPPH, ABTS, and FRAP from each other. DPPH = 2,2-diphenyl-1-picrylhydrazyl assay; FRAP = ferric reducing antioxidant power assay; ABTS $=$ 2,2-azinobis(3-ethylbenzothiazoline-6-sulfonic acid) assay; VitE = vitamin E; TPC = total phenolic content. 
$\beta$-carotene clearly formed a distinct group and the others (FRAP, ABTS, vitamin E, and TPC) more closely connected to each other.

\section{CONCLUSIONS}

The current work was conducted to evaluate the effect of using grains versus commercial culture on the antioxidant capacity of kefir from cow and ewe milks. Culture type (grains or commercial starter) had a direct influence on the antioxidant capacity of kefir samples during fermentation and storage. Kefir made from ewe milk had higher antioxidative levels than that made from cow milk, and kefir samples fermented by grains gave higher antioxidant capacity for DPPH and the highest ABTS results were obtained in kefir samples fermented by starter culture at the end of storage. These findings require further investigations to purify and identify each potential antioxidant component in kefir (i.e., peptides, lipids, phenolic compounds, and enzymes). In addition, in vivo studies are necessary to evaluate possible beneficial health effects of kefir, such as protection from free radical damage.

\section{ACKNOWLEDGMENTS}

The authors are grateful to the Commission of Scientific Research Projects of Uludag University [Bursa, Turkey; QUAP (Z) 2012/7] for the financial support of this study.

\section{REFERENCES}

Aloglu, H. S., and Z. Oner. 2011. Determination of antioxidant activity of bioactive peptide fractions obtained from yogurt. J. Dairy Sci. 94:5305-5314.

Arslan, S. 2015. A review: Chemical, microbiological and nutritional characteristics of kefir. CYTA J. Food 13:340-345.

Bartosz, G. 2013. Food Oxidants and Antioxidants: Chemical, Biological, and Functional Properties. CRC Press. Boca Raton, FL.

Barukčić, I., L. Gracin, A. R. Jambrak, and R. Božanić. 2017. Comparison of chemical, rheological and sensory properties of kefir produced by kefir grains and commercial kefir starter. Mljekarstvo 67:169-176.

Benzie, I. F., and J. J. Strain. 1996. The ferric reducing ability of plasma (FRAP) as a measure of "antioxidant power": the FRAP assay. Anal. Biochem. 239:70-76.

Boskou, D., and I. Elmadfa. 2010. Frying of Food: Oxidation, Nutrient and Non-Nutrient Antioxidants, Biologically Active Compounds and High Temperatures. 2nd ed. CRC Press, Boca Raton FL.

Calligaris, S., L. Manzocco, M. Anese, and M. C. Nicoli. 2004. Effect of heat-treatment on the antioxidant and pro-oxidant activity of milk. Int. Dairy J. 14:421-427.

Cao, G., and R. L. Prior. 1998. Comparison of different analytical methods for assessing total antioxidant capacity of human serum. Clin. Chem. 44:1309-1315.

Chen, J., H. Lindmark-Månsson, L. Gorton, and B. Akesson. 2003. Antioxidant capacity of cow milk as assayed by spectrophotometric and amperometric methods. Int. Dairy J. 13:927-935.

Chen, Z., J. Shi, X. Yang, B. Nan, Y. Liu, and Z. Wang. 2015. Chemical and physical characteristics and antioxidant activities of the exopolysaccharide produced by Tibetan kefir grains during milk fermentation. Int. Dairy J. 43:15-21.

Correia, I., A. Nunes, I. F. Duarte, A. Barros, and I. Elgadillo. 2004. Sorghum fermentation followed by spectroscopic techniques. Food Chem. 90:853-859.

Dalling, M. J. 1986. Plant Proteolytic Enzymes. CRC Press, Boca Raton, FL.

de Oliveira Leite, A. M., M. A. Miguel, R. S. Peixoto, A. S. Rosado, J. T. Silva, and V. M. Paschoalin. 2013. Microbiological, technological and therapeutic properties of kefir: A natural probiotic beverage. Braz. J. Microbiol. 44:341-349.

Ehsan, K., O. Ehsan, H. Rudi, and H. Z. E. Jaafar. 2010. Solid state fermentation effects on pistachio hulls antioxidant activities. King Khalid Univ. Res. J. 15:260-266.

Ertan, K., D. Bayana, O. Gokce, J. T. Alatossava, Y. Yilmaz, and O. Gursoy. 2017. Total antioxidant capacity and phenolic content of pasteurized and UHT-treated cow milk samples marketed in Turkey. Akademik Gida. 15:103-108.

Gao, X., and B. Li. 2016. Chemical and microbiological characteristics of kefir grains and their fermented dairy products: A review. Cogent Food Agric. 2:127-152.

Gupta, A., B. Mann, R. Kumar, and R. Sangwan. 2009. Antioxidant activity of cheddar cheeses at different stages of ripening. Int. J Dairy Technol. 62:339-347.

Halah, M. F., and N. S. Mehanna. 2011. Use of natural plant antioxidant and probiotic in the production of novel yogurt. J. Evol. Biol. Res. 3:12-18.

Kesenkas, H., N. Dinkci, K. Seckin, O. Kinik, and S. Gonc. 2011. Antioxidant properties of kefir produced from different cow and soy milk mixtures. J. Agric. Sci. 17:253-259.

Kim, G. N., H. D. Jang, and C. I. Kim. 2007. Antioxidant capacity of caseinophosphopeptides prepared from sodium caseinate using Alcalase. Food Chem. 104:1359-1365.

Kitts, D. D. 2005. Antioxidant properties of casein-phosphopeptides. Trends Food Sci. Technol. 16:549-554.

Korpela, R., M. Ahotupa, H. Korhonen, and E. L. Syvaoja. 1995 Antioxidant properties of cow's milk. Pages 157-159 in Proceedings of the NJF/NMR seminar No. 252, January 13-15, 1995. S. Mantere Alhonen and K. Maijala, ed. Scandinavian Association of Agricultural Scientists Publication, Turku, Finland.

Kullisaar, T., E. Songisepp, M. Mikelsaar, K. Zilmer, T. Vihalemm, and M. Zilmer. 2003. Antioxidative probiotic fermented goats' milk decreases oxidative stress-mediated atherogenicity in human subjects. Br. J. Nutr. 90:449-456.

Landete, J. M. 2013. Dietary intake of natural antioxidants: Vitamins and polyphenols. Crit. Rev. Food Sci. Nutr. 53:706-721.

Lin, M. Y., and C. L. Yen. 1999. Antioxidative ability of lactic acid bacteria. J. Agric. Food Chem. 47:1460-1466.

Lindmark-Månsson, H., and B. Akesson. 2000. Antioxidative factors in milk. Br. J. Nutr. 84:S103-110.

Liu, J. R., Y. Y. Lin, M. J. Chen, L. J. Chen, and C. W. Lin. 2005. Antioxidative activities of kefir. Asian-australas. J. Anim. Sci. 18:567-573.

López-Pedrera, C., N. Barbarroja, Y. Jimenez-Gomez, E. CollantesEstevez, M. A. Aguirre, and M. J. Cuadrado. 2016. Oxidative stress in the pathogenesis of atherothrombosis associated with anti-phospholipid syndrome and systemic lupus erythematosus: New therapeutic approaches. Rheumatology 55:2096-2108.

Lourens-Hattingh, A., and B. C. Viljoen. 2001. Review: Yoghurt as probiotic carrier food. Int. Dairy J. 11:1-17.

Najgebouer-Lejko, D., T. Grega, and M. Tabaszewska. 2014. Yoghurts with addition of selected vegetables; acidity, antioxidant properties and sensory quality. Acta Sci. Pol. Aliment. 13:35-42.

Nishino, T., H. Shibahara-Sone, H. Kikuchi-Hayakawa, and F. Lshikawa. 2000. Transit of radical scavenging activity of milk products prepared by Maillard reaction and Lactobacillus casei strain Shirota fermentation through the hamster intestine. J. Dairy Sci. 83:915-922.

O'Connella, J. E., and P. F. Fox. 2001. Significance and applications of phenolic compounds in the production and quality of milk and dairy products: A review. Int. Dairy J. 11:103-120. 
Perna, A., I. Intaglietta, A. Simonetti, and E. Gambacorta. 2013. Effect of genetic type and casein haplotype on antioxidant activity of yogurts during storage. J. Dairy Sci. 96:3435-3441.

Pizzino, G., N. Irrera, M. Cucinotta, G. Pallio, F. Mannino, V. Arcoraci, F. Squadrito, D. Altavilla, and A. Bitto. 2017. Oxidative stress: Harms and benefits for human health. Oxid. Med. Cell. Longev. 2017:8416763.

Prado, M. R., L. M. Blandón, L. P. S. Vandenberghe, C. Rodrigues, G. R. Castro, V. Thomaz-Soccol, and C. R. Soccol. 2015. Milk kefir Composition, microbial cultures, biological activities, and related products. Front. Microbiol. 6:1177.

Pulido, R., M. Hernández-García, and F. Saura-Calixto. 2003. Contribution of beverages to the intake of lipophilic and hydrophilic antioxidants in the Spanish diet. Eur. J. Clin. Nutr. 57:1275-1282.

Rashidinejad, A., E. J. Birch, D. Sun-Waterhouse, and D. W. Everett. 2015. Total phenolic content and antioxidant properties of hard low-fat cheese fortified with catechin as affected by in vitro gastrointestinal digestion. Lebensm. Wiss. Technol. 62:393-399.

Rival, S. G., C. G. Boeriu, and H. J. Wichers. 2001. Caseins and casein hydrolysates. 2. Antioxidative properties and relevance to lipoxygenase inhibition. J. Agric. Food Chem. 49:295-302.

Rogelj, I., and B. Perko. 1998. Fermentation of goat and cow milk with different lactic acid starter cultures. Pages 262-267 in Basis of the Quality of the Typical Mediterranean Animal Products. J. C. Flamant, D. Gabinâ, and M. Espejo Díaz, ed. Wageningen Press, Wageningen, the Netherlands.

Rosa, D. D., M. M. S. Dias, Ł. M. Grześkowiak, S. A. Reis, L. L. Conceição, and M. C. G. Peluzio. 2017. Milk kefir: Nutritional, microbiological and health benefits. Nutr. Res. Rev. 30:82-96.

Sabokbar, N., F. Khodaiyan, and M. Moosavi-Nasab. 2015. Optimization of processing conditions to improve antioxidant activities of apple juice and whey based novel beverage fermented by kefir grains. J. Food Sci. Technol. 52:3422-3432.

Sah, B. N., T. Vasiljevic, S. McKechnie, and O. N. Donkor. 2015. Effect of refrigerated storage on probiotic viability and the production and stability of antimutagenic and antioxidant peptides in yogurt supplemented with pineapple peel. J. Dairy Sci. 98:5905-5916.

Sahin, S., O. Aybastier, and E. Isik. 2013. Optimisation of ultrasonic-assisted extraction of antioxidant compounds from Artemisia absinthium using response surface methodology. Food Chem. 141:1361-1368.

Sahin, S., E. Isik, O. Aybastier, and C. Demir. 2012. Orthogonal signal correction-based prediction of total antioxidant activity using partial least squares regression from chromatograms. J. Chemometr. $26: 390-399$

Shori, A. B., and A. S. Baba. 2013. Antioxidant activity and inhibition of key enzymes linked to type-2 diabetes and hypertension by $A z a-$ dirachta indica-yogurt. J. Saudi Chem. 17:295-301.

Smet, K., K. Raes, J. De Block, L. Herman, K. Dewettinck, and K. Coudijzer. 2008. A change in antioxidative capacity as a measure of onset to oxidation in pasteurized milk. Int. Dairy J. 18:520-530.

Songisepp, E., T. Kullisaar, P. Hütt, P. Elias, T. Brilene, M. Zilmer, and M. Mikelsaar. 2004. A new probiotic cheese with antioxidative and antimicrobial activity. J. Dairy Sci. 87:2017-2023.

Suetsuna, K., H. Ukeda, and H. Ochi. 2000. Isolation and characterization of free radical scavenging activities peptides derived from casein. J. Nutr. Biochem. 11:128-131.

Sun, Y. P., C. C. Chou, and R. C. Yu. 2009. Antioxidant activity of lactic fermented Chinese cabbage. Food Chem. 115:912-917.

Taylor, M. J., and T. Richardson. 1980. Antioxidant activity of skim milk: Effect of heat and resultant sulfhydryl groups. J. Dairy Sci. 63:1783-1795.

Virtanen, T., A. Pihlanto, S. Akkanen, and H. Korhonen. 2007. Development of antioxidant activity in milk whey during fermentation with lactic acid bacteria. J. Appl. Microbiol. 102:106-115.

Wszolek, M., A. Y. Tamime, D. D. Muir, and M. N. I. Barclay. 2001. Properties of kefir made in Scotland and Poland using cow, caprine and ewe milk with different starter cultures. Lebensm. Wiss. Technol. 34:254-261.

Yilmaz-Ersan, L., T. Ozcan, A. Akpinar-Bayizit, and S. Sahin. 2015. The antioxidative capacity of kefir produced from goat milk. Int. J. Chem. Eng. Appl. 7:22-26.

Zulueta, A., A. Maurizi, A. Frígola, M. J. Esteve, R. Coli, and G. Burini. 2009. Antioxidant capacity of cow milk, whey and deproteinized milk. Int. Dairy J. 19:380-385. 